\title{
University-Industry Partnership: Understanding the Current Situation between UMP and DRB-HICOM
}

\author{
Normah binti Othman", Nabila Abdul Malek \\ Centre for Modern Languages \& Human Sciences, Universiti Malaysia Pahang, Lebuhraya Tun Razak, 26300 Gambang, Kuantan, Pahang, \\ Malaysia \\ normah_othman@yahoo.com, bellamalek11@yahoo.com
}

\begin{abstract}
A survey was conducted to get an in depth overview of the current condition of UMP in relation to her partnership with an automotive and manufacturing industry. The dean and the ex-dean of the Faculty of Mechanical Engineering, UMP were interviewed and the results show that both of them were not happy with the current collaboration situation with the automotive industry. This paper discusses their opinions about the current situation and their suggestions for the improvement of their university's partnership with the automotive industry so that both parties get equal gain and benefits.
\end{abstract}

Keywords University-Industry Partnership, Mechanical Engineering, Mechanical Education, Automotive Engineering, Manufacturing Engineering

\section{Introduction}

DRB-HICOM Berhad ("DRB-HICOM) is one of Malaysia's leading companies listed on the Main Market of Bursa Malaysia Securities Berhad, playing an integral role in the nation's road to industrialisation. HICOM had been instrumental in leading the nation's drive towards industrialisation and among its major achievements was the development of the National Car Project. Meanwhile, DRB-HICOM was instrumental in the development of Malaysia's first national motorcycle and Malaysian-made truck in collaboration with international automakers. DRB-HICOM is a fully integrated automotive company involved in every link of the automotive chain: from the manufacture of automotive components and assembly to distribution and after sales support for a wide range of vehicles - motorcycles to passenger, commercial, defence and customised vehicles such as buses, ambulances, police vehicles, fire trucks and garbage compactors. While concentrating on the domestic market, DRB-HICOM has made inroads into the export market, especially in component manufacture and assembly. DRB-HICOM has world class assembly and manufacturing facilities and the expertise for complex and precision engineering. Apart from serving our own automotive needs, they are also contract manufacturers for national and global carmakers and OEMs (Original Equipment Manufacturers). On the distribution front, DRB-HICOM has strengthened its

* Corresponding author:

normah_othman@yahoo.com(Normah binti Othman)

Published online at http://journal.sapub.org/economics

Copyright (C) 2012 Scientific \& Academic Publishing. All Rights Reserved position, with a growing number of franchises from international automakers. Most importantly, it is evolving from a franchise holder to become a joint venture partner with manufacturers such as Honda, Isuzu and Suzuki. ${ }^{1}$

Universiti Malaysia Pahang was established as a public technical university by the Malaysian government on 16 February 2002. Incorporated under the Universities and University Colleges Act 1971 by the Royal Decree of His Majesty the Yang DiPertuan Agong, Kolej Universiti Kejuruteran \& Teknologi Malaysia (KUKTEM) was set up as a competency-based technical university, specializing in engineering and technology. The University College of Engineering \& Technology Malaysia currently operates on a temporary campus in Gambang, Pahang. The temporary campus was formerly an industrial complex owned by MEC. The university's permanent campus is located in Pekan, which is currently still under construction.

On 8 October, 2006, the Malaysian government has agreed to rename KUKTEM to Universiti Malaysia Pahang. The change of name is because the words 'university college' (Kolej Universiti) tend to give impression to the public that KUKTEM is a "lower standard" institution of higher education compared to other universities such as University of Malaya. Many employers also tend to think that KUKTEM graduates are not competent enough as they graduated from a university college and not a full university. Therefore, the change of name is finally granted by the Malaysian government for the sake of the graduates and also to correct the wrong mind-set of the public towards the university colleges in Malaysia. The university consists of 17 departments/units and 7 faculties (some are known as centre). One of the faculties in UMP is Faculty of Mechanical Engineering. ${ }^{2}$

The Faculty of Mechanical Engineering has a reputation 
within industry and academia for producing highly trained, competent and professional mechanical engineers. The faculty offer students the choice of a range of highly demand B. Eng. courses. Two postgraduate $\mathrm{PhD}$ and MSc courses are also offered in the field of Mechanical, Automotive and Manufacturing Engineering. Five academic programmes for bachelor level and one for diploma level are being offered in this faculty which are Bachelor of Mechanical Engineering, Bachelor of Mechanical Engineering with Automotive Engineering, Bachelor of Mechanical Engineering with Manufacturing Engineering, Bachelor of Mechanical Engineering with Industry Engineering, Bachelor of Mechanical Engineering with Biomechanical and Diploma of Mechanical Engineering. The faculty hope to be a centre for channelling innovative research products and expert services in Automotive and Manufacturing engineering to the local industries. It will also serve as a catalyst in the development of the East Coast Industrial Corridor through programs such as technology transfer, staff exchange, training and other services relating to chemical and natural resources engineering. ${ }^{3}$

In line with the university's vision to be a world-class technological university and in line with the university's mission to provide high quality education, research and services in engineering and technology in a culture of creativity and innovation, the collaboration between UMP and DRB - Hicom will benefits both parties especially in developing the syllabus and course content for students in Faculty of Mechanical Engineering who at times are the most related to DRB - Hicom especially in the automotive and manufacturing field.

\section{Research Objectives}

This study embarks on the following objectives:

1. To assess the current condition of UMP, in relation to auto engineering and manufacturing engineering.

2. To assess the current course content taught at the Mechanical Engineering Faculty in UMP.

3. To make recommendation based on the research, and find a long-term partnership between DRB-HICOM and UMP.

\section{Methodology}

This research employed a survey in the form of interviews. Two interview sessions were conducted with the dean and the ex-dean of the faculty.

\section{Results and Discussion}

The dean and the ex-dean of Mechanical Engineering Faculty were interviewed in order to get an in depth overview of the current condition of UMP and DRB-HICOM in relation to automotive and manufacturing engineering. In response to the interview questions, the dean of Mechanical Engineering Faculty is clearly not happy with the current collaboration between UMP and DRB-HICOM. He mentioned that the industry generally does not believe that the university can deliver on time. This statement is supported by the response from the ex-dean who mentioned that the industry is very outcome based oriented. They want full commitment from the university if they were to collaborate together successfully. As stated by Normah (2011), working cultures at the universities and the industries are different. The industries cannot wait for long to complete any work because lengthening of work duration can cause industry staffs to lose their jobs. This lack of trust is the main problem in the course of collaboration with the industry.

However, both dean and ex-dean agree that the university can benefits a lot from this collaboration if it is successful. According to the dean, the university can benefit from the direction of research and also development of successful products. This is supported by Normah (2011), where she stated that the industry has a limited manpower and expertise to solve their problems, thus the industry needs help from the university since the university has many experts in many fields. As for the ex-dean, he mentioned that the successful collaboration can give exposure of the real working environment to our staff and students.

When talking about the relevancy of the current mechanical course content provided by Faculty of Mechanical Engineering in relation to the industry's need, the dean response was that basically any degree program only provides the fundamentals but generally the university updates the curriculum to be relevant to the current needs. Additionally, the ex-dean also has the same belief that the university only provides general knowledge to the students. The university try to creates subjects which are related to the automotive and manufacturing field in general and at the same time related to the industry's need although it is not hundred per cent covers what the industry want.

As for the requirement needed from the students before they are allowed to go for industrial practice, the dean mentioned that the acquisition of the fundamental knowledge is vital coupled with problem solving skills. In addition, the ex-dean emphasize on the strong basic soft skills especially confident. This is because the real working environment is not the same as in the laboratory. The students need to be able to adapt themselves to the working environment. This was supported by Normah (2011), that students should be equipped with an overall knowledge that includes not only technical knowledge but also soft skills that enable them to be good leaders, good communicators and good organisers.

From the dean's experiences, he mentioned that the students are not doing so well in their industrial practical because of mismatches. Sometimes the industries do not give the proper training perhaps because they are too busy. On the other hand, the ex-dean supported the idea that our students are doing well in their industrial practical because some of 
his students have been absorb by the industry right after they graduated and he mentioned that lots of our students become a successful person after they graduated.

When asked about the feedbacks the university get from the industry about the students' performance during their industrial practical, the dean is not sure. Similarly, the ex-dean stated that it is difficult to get the feedbacks from the industry. However, according to the ex-dean, some of his friends working in the industry did mention that our students are actually lack of soft skills especially in communication skill. This is because the industry operates fully in English but our students do not have strong basic English communication skill. These responses are actually in contrast with the finding from Normah (2011) research, where she mentioned that the university do not give the chance for the industry to give real feedback about students' performance because the lecturers did not make any effort to see the staff from the industries when they go to the industry to supervise their students. In short, there should be a proper channel for the industry to report about the students' performance during their industrial training. In that way, both parties can benefits from the report and improvement can be made.

In response to the question whether this industry partnership will benefits the students or not, the dean said that it will benefit greatly. Likewise, the ex-dean also said that in the long run this collaboration is very good because it can provide job opportunities to our students. Besides, DRB-HICOM has bought Proton. So, this will give more job opportunities to our students in the near future.

The dean agrees and disagrees on the statement that the facilities and equipment in the laboratory can help to prepare the students for the real industry environment. He agrees for the basic knowledge and skills that the students can get but he disagrees for the current industrial needs perhaps the new technologies used in the industries nowadays. But as he mentioned, it is not the job of the university to provide ready-made engineers for the industry. Likewise, the ex-dean also mentioned that DRB-HICOM is more to assemble business and we do not have many facilities and equipment for assembly. Maybe because of this, according to Normah (2011), the industry comments that our students are not ready to work directly in industries. They experienced practical shock when they first arrive at the industries for training and the industries need to facilitate them from the beginning when they start their industrial training.

According to the dean, the university have a long way to established in automotive and manufacturing engineering field. In contrast, the ex-dean belief that UMP is doing good in relation to automotive and manufacturing field because people from the industries are starting to know and acknowledge the graduates from UMP. For example, the ex-dean has built human connection between DRB-HICOM and UMP in the earlier days of UMP and as a result, our students are now accepted to do industrial practice in DRB-HICOM.

Lastly, the dean mentioned that being relevant and producing the high level of knowledge and skills that is required by future industry in Malaysia are the challenges faced by the mechanical engineering education in our country. As for the ex-dean, the moulding of the raw material that is our students is very important and a big challenge because most of our students are Bumiputra and they are lacking in mastering the basic knowledge of mathematics and physics because these two subjects are the core subjects in engineering field not just mechanical engineering.

In conclusion, from the results of the interviews it shows that both parties, the university and the industry need to understand the differences they have especially in terms of working culture if we want to make sure that this industry partnership collaboration become successful. Moreover, the industry also needs to understand that the university can only provide general fundamental knowledge to the students because it is the industry's responsibility to give exposure of the real working environment to these students by helping the students to adapt and applied their knowledge in the real situation.

\section{Conclusions and Recommendation}

The results from the interview and the questionnaire show that the current course content taught at the Mechanical Engineering Faculty in UMP is sufficient for the students and in line with the industry needs. However, some improvement is needed to make sure that the syllabus is not out-dated. In addition, the university should provide more facilities for practical purpose to enhance the students understanding of the subject. Sufficient facilities and equipment can give exposure to the students on the processes involve in the real industry and it helps the students to visualize the actual working environment prior to their industrial practical.

Looking at the current condition of UMP, in relation to auto engineering and manufacturing engineering, it is agreed that the university have a long way to established in automotive and manufacturing engineering field because we are still new and it is hoped that the collaboration between UMP and DRB-HICOM will enable the sharing of expertise and technology that will greatly benefits both parties. However, we believe that UMP is doing well in relation to automotive and manufacturing field in the time being because people from the industries are starting to know and acknowledge the graduates from UMP.

As for recommendation, it is suggested that the university and the industry try to understand the differences they have because our main concern is the students. It is the university's mission to provide high quality education to the students. Thus, the cooperation from the industry is vital. It is hoped that the students will be given a proper job prospects during their industrial practical even though the duration is only 12 weeks. This is to ensure that the students get the real exposure of the working environment. The university cannot do this alone without the help of the industry. In short, a successful university industry-partnership between UMP and 
DRB-HICOM can help to produce knowledgeable and skilled engineer that is required by future industry in $\mathrm{Ma}-$ laysia.

\section{ACKNOWLEDGEMENTS}

I would like to thank the Ministry of Higher Education (MOHE) for granting the FRGS grant to me to conduct this research.

\section{REFERENCES}

[1] Retrieved from http://www.drb-hicom.com

[2] Retrieved from http://en.wikipedia.org/wiki/Universiti_Mala ysia_Pahang

[3] Retrieved from http://fkm.ump.edu.my

[4] Jones, L. M. (2012). University-Industrial Research Collaboration - Advantages of the Collaborative Relationships, Disadvantages of the Collaborative Relationships. Retrieved from http://education.stateuniversity.com/pages/2519/Univer sity-Industrial-Research-Collaboration.html

[5] Normah Othman. (2011). Factors Contributing to the Effectiveness of a University-Industry Partnership. Sino-US English Teaching, 8(11), 681-688. 